\title{
Self-rated health disparities among disadvantaged older adults in ethnically-diverse urban neighborhoods in a Middle Eastern country
}

Sibai, Abla Mehio ${ }^{1}$; Rizk, Anthony ${ }^{2}$; Chemaitelly, Hiam ${ }^{3}$

${ }^{1}$ Department of Epidemiology and Population Health, Faculty of Health Sciences, American University of Beirut, Lebanon, P.O. Box 11-0236, Riad El Solh 1107 2020, Beirut, Lebanon. Telephone: + (961) 1350000 ext 4640. Email: am00@aub.edu.lb.

2 Department of Epidemiology and Population Health, Faculty of Health Sciences, American University of Beirut, Lebanon, P.O. Box 11-0236, Riad El Solh 1107 2020, Beirut, Lebanon. Telephone: + (961) 1350000 ext 4640. Email: ar47@aub.edu.lb.

${ }^{3}$ Corresponding author: Infectious Disease Epidemiology Group, Weill Cornell Medicine- Qatar, Qatar Foundation - Education City, P.O. Box 24144, Doha, Qatar. Telephone: + (974) 4492-8443. Fax: + (974) 4492-8422. E-mail: hsc2001@qatarmed.cornell.edu.

Word Count: manuscript: 6,970; abstract: 286

Running head: SRH disparities among ethnically diverse older adults

\section{Funding}

This publication was made possible by the partial support provided to authors by the Biostatistics, Epidemiology, and Biomathematics Research Core at the Weill Cornell Medical College in Qatar. This study was also part of a larger multidisciplinary research project on urban health supported by grants from the Wellcome Trust, the Mellon Foundation, and the Ford Foundation. The statements made herein are solely the responsibility of the author. 


\begin{abstract}
Objectives: This paper examines differentials in self-rated health (SRH) among older adults (aged 60+ years) across three impoverished and ethnically-diverse neighborhoods in post-conflict Lebanon and assesses whether variations are explained by social and economic factors.
\end{abstract}

Design: Data were drawn from the Older Adult Component $(n=740)$ of the Urban Health Survey, a population-based cross-sectional study conducted in 2003 in a formal community (Nabaa), an informal settlement (Hey El-Sellom) and a refugee camp for Palestinians (Burj El-Barajneh) in Beirut, Lebanon. The role of the social capital and economic security constructs in offsetting poor SRH was assessed using multivariate ordinal logistic regression analyses.

Results: Older adults in Nabaa fared better in SRH compared to those in Hey El-Sellom and Burj El-Barajneh, with a prevalence of good, average, and poor SRH being respectively, $41.5 \%, 37.0 \%$, and $21.5 \%$ in Nabaa, 33.3\%, $23.9 \%$ and $42.7 \%$ in Hey ElSellom, and 25.2\%, 31.3\%, 43.5\% in Burj El-Barajneh. The economic security construct attenuated the odds of poorer SRH in Burj El-Barajneh as compared to Nabaa from 2.57 (95\% CI: $1.89-3.79)$ to 1.42 (95\% CI: 0.96-2.08), but had no impact on this association in Hey El-Sellom (OR: 2.12, 95\% CI: 1.39-3.24). The incorporation of the social capital construct in the fully adjusted model rendered this association insignificant in Hey ElSellom (OR: 1.49, 95\% CI: 0.96-2.32), and led to further reductions in the magnitude of the association in Burj El-Barajneh camp (OR: 1.18, 95\% CI: 0.80-1.76).

Conclusions: The social context in which older adults live and their financial security are key in explaining disparities in SRH in marginalized communities. Social capital and economic security, often overlooked in policy and public health interventions, need to be integrated in dimensions of well-being of older adults, especially in post-conflict settings.

Keywords: self-rated health; ethnicity; displacement; older adults; urban health; conflict; Lebanon. 


\section{Introduction}

As countries undergo rapid demographic transitions, population aging presents the challenge of mitigating the rising burden of co-morbidities, the pervasive lack of ageappropriate support services, and the growing health inequalities in later life (Bloom et al. 2015). The need to inform policy led to the development of various indicators to characterize health among older adults including quality of life and well-being, and to assess determinants of health inequalities in old age. While the West is spearheading efforts in geriatric research, the epidemiology of aging remains poorly understood in other settings including Arab countries of the Mediterranean region. Here, population aging is doubly challenged by chronic political and economic instability, waves of displacement caused by the recent regional turmoil, and socioeconomic disparities across sectarian and ethnically-diverse populations.

Located at the heart of the Middle East, Lebanon is a middle-income country that continues to be heavily affected by over 16 years of armed conflict and instability from 1975 until 1992. Amongst Arab countries, Lebanon has the highest percentage of older people aged 65 years and above (8.4\%) (United Nations Population Division 2012). Close to $87 \%$ of the population, estimated at around 4 million people, are clustered in urban areas and a substantial proportion reside in the outskirts of the capital, Beirut (United Nations Population Division 2011). The aim of this work is to characterize older adults' self-perception of health across three underprivileged ethnically-diverse urban communities affected by displacement waves in Lebanon and to explore whether differential in access to social and economic resources can mitigate health disparities.

\section{Self-rated health: a comprehensive measure of well-being}

A well-established quality of life indicator among older adults is self-rated health 
$(\mathrm{SRH})$ - it has been described in the literature as a robust and universal measure of an individual's current and future health status that encompasses the physical, mental and social dimensions of well-being (Jylha 2009; Mavaddat, Valderas, et al. 2014;

Abdulrahim and El Asmar 2012). Beyond its ability to reflect on an individual's quality of life, SRH is also key in predicting mortality, even after controlling for age, gender, socioeconomic status and comorbidities (Idler and Benyamini 1997; DeSalvo et al. 2006; Stenholm et al. 2015; Mavaddat, Parker, et al. 2014).

\section{Determinants of SRH: theoretical perspective}

Building on Bourdieu's theoretical approach, better SRH in old age appears to be largely determined by access to psychosocial and material resources as well as the characteristics of the places in which older people live (Carpiano 2006; Berkman 2000; Eriksson 2011; Kim and Kawachi 2006). Bourdieu's social capital theory emphasizes "the collective resources of groups that can be drawn upon by individual group members for procuring benefits and services in the absence or in conjunction with their own economic capital" (Carpiano 2006), which in turn appear to be linked to better health outcomes (Eriksson 2011; Berkman 2000; Kim and Kawachi 2006). Social capital resources include the structural characteristics of a neighborhood (neighborhood's socio-economic conditions, perceived satisfaction with features and services), social connectedness (networks' formation, strength of social ties, and social participation), social norms (trust, reciprocity), and social support (resources that can be mobilized to promote an individual's well-being) (Carpiano 2006; Linden-Bostrom, Persson, and Eriksson 2010). Additionally, economic capital has been suggested to play a role in facilitating access to social capital resources since the ability to acquire services or amenities, such as a phone, or a car, may as well promote social connectedness (Kawachi et al. 1997; Kawachi, Subramanian, and Almeida-Filho 2002). 


\section{Mechanisms linking social capital and economic capital to health}

Social capital through its various constructs has been shown to attenuate the impact of adverse life circumstances on poor health outcomes including SRH through both direct and indirect pathways (Kawachi, Subramanian, and Almeida-Filho 2002; Chen et al. 2015; Kim and Kawachi 2006; Linden-Bostrom, Persson, and Eriksson 2010; Mavaddat, Valderas, et al. 2014; Eriksson 2011). Specifically, social connectedness, reciprocity, and social support were noted to have a direct impact on maximizing access to resources and addressing individuals' unmet needs (Kawachi, Subramanian, and Almeida-Filho 2002; Eriksson 2011; Pollack and von dem Knesebeck 2004; Kawachi, Subramanian, and Kim 2008). More specifically, higher levels of trust have been also associated with lower rates of cardiovascular and cerebrovascular conditions, cancers, injuries, and even mortality (Kawachi et al. 1997; Berkman, Leo-Summers, and Horwitz 1992). Social participation has been shown to activate cognitive systems and promote positive feelings of meaningfulness and belonging, and more generally mental health (Eriksson 2011). The impact of social capital on health may also follow indirect pathways. Studies have demonstrated that individuals with higher levels of social capital are less likely to engage in risky behaviors such as smoking, poor dietary intake and physical inactivity, which are pre-disposing factors for many chronic conditions (Kawachi, Subramanian, and Kim 2008). The link between lower levels of social capital among older adults and poor SRH has also been established (Pollack and von dem Knesebeck 2004; Nummela et al. 2009) with multi-level analyses reaching similar findings (Kim and Kawachi 2006; Subramanian, Kim, and Kawachi 2002).

Similarly, the association between economic security and better health outcomes including SRH is well documented (Subramanian, Kim, and Kawachi 2005; Subramanyam et al. 2009; Smith 1999). Besides, the affordability of higher living 
standards and the ability to seek improved care for various health conditions, a capital of economic resources, has been associated with a sense of financial security-a buffering factor against physical and emotional stress, especially among older adults (Grundy and Sloggett 2003; Huisman et al. 2013; Smith 1999; Kawachi, Subramanian, and Almeida-Filho 2002; Chemaitelly et al. 2013).

The limited data available from the Middle East and North Africa region suggest a positive association between lack of community services, poor housing quality, a derelict infrastructure, and the prevalence of chronic illness (Habib et al. 2009; Habib et al. 2011). Some studies have gaged the accumulated burdens of unemployment and unpaid domestic labor, as well as shrinking social networks, on the health of older persons (Habib et al. 2006; Webster et al. 2015). Others portrayed the gendered dimensions of poor SRH among older persons in urban and informal neighborhoods (Ahmad et al. 2013; Chemaitelly et al. 2013). However, the impact of successive displacement waves on the well-being of older adults and on the social dynamics and economic security among displaced populations remains unexplored.

\section{Setting and context}

This research was conducted in three neighborhoods in Lebanon located in the "poverty belt' surrounding the capital city, Beirut: an eastern suburb (Nabaa) and two southern suburbs (Hey El-Sellom and Burj El-Barajneh). Our choice of neighborhoods was informed by their historical trajectory as their formation is, in part, the result of displacement waves caused by local and regional conflicts. These neighborhoods are geographically defined, and differ not only with respect to their infrastructure, but also with respect to their ethnic and sectarian make-up which renders social interactions across these communities highly unlikely. In this work, we define ethnicity as a socially-constructed identity based on factors inherent to a group such as background, 
culture, and religion which dictate social standing, political power, and access to services (Abdulrahim and Khawaja 2011).

Nabaa is an established formal neighborhood that used to be home for Lebanese with mixed religious backgrounds. Following years of civil strife, Nabaa became largely inhabited by Lebanese Christian families who were either among the original residents of the neighborhood or displaced from other areas (Makhoul, Ghanem, and Ghanem 2003). The neighborhood benefits from developmental plans for that area and a large number of churches, schools and commercial and industrial institutions can be also found in its vicinity.

On the other hand, Hey El-Sellom is an agricultural land that slowly became an informal settlement largely inhabited by Lebanese Muslims moving from rural villages in the South of Lebanon to seek employment in the capital or to flee war and conflict. Although settlements in Hey El-Sellom evolved from tin huts to more concrete structures, these settlements are still considered illegal by the government and lack the appropriate infrastructure to serve its growing population. Residents of Hey El-Sellom are also unique in that they tend to have their extended family living in their original remote villages rather than within the neighborhood (Khawaja et al. 2006; Makhoul J. 2003).

Unlike Nabaa and Hey El-Sellom, Burj El-Barajneh was formed as a temporary settlement to house Palestinian refugees following the 1948 exodus. The Lebanese State has withheld major development of Burj El-Barajneh camp's infrastructure, and thus it has remained largely neglected in terms of infrastructure and basic public services. Palestinian refugees in Lebanon also face legal restrictions in terms of work and travel, and consequently, are at an economic disadvantage compared to the Lebanese population. 


\section{Study objectives}

This study comes to fill a gap in the aging literature for Arab countries and aims to contribute to a better understanding of the social and economic determinants of health inequality in later life. The study is in tandem with the growing literature on 'Aging in Place' and the associated policy direction that stresses the importance of reinforcing the social and physical environment to ensure healthy aging in one's home and community, and the prevention of isolation, marginalization, and the costly option of unwanted institutional care (World Health Organization 2007).

The study addresses three specific research questions and hypotheses. Firstly, are there differentials in SRH among older adults across the three communities, Nabaa, Hey ElSellom and Burj El-Barajneh? We hypothesize that older adults in Nabaa, a formal community, will express better SRH than older adults residing in the informal settlement of Hey El-Sellom or in the Palestinian refugee camp of Burj El-Barajneh. Secondly, how do the three communities vary in terms of social capital and economic security? We hypothesize that social capital will be highest in Nabaa, followed by Burj el Barajneh camp, and subsequently Hey El-Sellom, while economic security will be higher in Nabaa and in Hey El-Sellom than in Burj El-Barajneh camp. And finally, can variations in social capital and economic security explain differences in SRH across the communities and what is the contribution of each of these constructs to SRH? We hypothesize that social capital and economic security contribute separately to SRH of older adults across the three communities under study, net of the effect of potential confounding factors. 


\section{Data and methods}

\section{Study design and data collection}

Data for this study were drawn from the Older Adult Component of the Urban Health Study (UHS), a large cross-sectional population-based study conducted by the Center of Research on Population Health of the Faculty of Health Sciences at the American University of Beirut during 2002-2003 in the three neighborhoods of Nabaa, Hey ElSellom and Burj El-Barajneh. Further details related to the design and conduct of the UHS have been described elsewhere (Khawaja and Mowafi 2006; Jawad, Sibai, and Chaaya 2009). Briefly, the UHS followed a two-stage sampling design, where a sample of 3,300 households was initially selected using a probability sampling proportional to population size. Older adults aged 60 years and over, regardless of religion or legal status, were subsequently invited to participate in the Older Adult Component survey. Institutionalized individuals, migrant workers and those residing in abandoned buildings were not approached. Out of 852 eligible older adults, 740 (86.8\%) completed the faceto-face interview. There were minor variations in response rate between communities: $85.8 \%$ in Nabaa, $83.1 \%$ in Hey El-Sellom, and 90.4\% in Burj El-Barajneh camp. Nonresponse was mainly attributed to residential change and no contact following three unsuccessful attempts. The interview took around 75 minutes to be completed. Less than $1 \%$ of older adults had missing or incomplete information and those were excluded from further analyses. The original UHS study and its various components were reviewed and approved by the Institutional Research Board of the American University of Beirut.

Data for the Older Adult Component of the UHS were collected using an interview schedule that comprehensively assessed a range of socio-demographic, health, social and economic indicators. The tool was constructed in Arabic and pilot-tested prior to its 
administration by trained university-level interviewers selected from the different communities. Consistency and quality control checks were performed at multiple levels of the data collection and data entry phases. Data were entered using CSpro software where automatic skips and further validity and consistency checks were applied. Questionnaires with detected inconsistencies were returned to the field for re-interview. The validity of the data was further ascertained through a systematic re-interview of $10 \%$ of the sample.

\section{Measures}

Our dependent variable, SRH, was assessed using a 5-point likert scale ranging from very good, good, average, poor and very poor health. Informed by the frequency distribution of the 5-point measure for SRH across the three communities and other scholarly work (Mellor and Milyo 2005; Wen et al. 2003), we analyzed SRH as an ordinal variable with three categories. Here, subjects who rated their health as 'very good' and 'good' were grouped as having 'good' SRH (coded as 0), those who reported 'average' SRH were considered as a separate category (coded as 1), whereas those who rated their health as 'poor' and 'very poor' were classified as having 'poor' SRH (coded as 2). Details of a sensitivity analysis performed to assess the robustness of our findings using the trichotomous SRH measure to that using the original measure are discussed in subsequent sections.

Social capital is a multidimensional construct which was operationalized based on seven subcomponents including locational capital, social anchorage, social participation, civic trust, reciprocity, hypothetical social support, and social networks (Lindstrom, Sundquist, and Ostergren 2001; Harpham, Grant, and Thomas 2002; Kim and Kawachi 2006; Carpiano 2006; Travis et al. 2004). Items describing these subcomponents $(n=21)$ are detailed in Table 2. Briefly, locational capital refers to self-perception of 
neighborhood characteristics and was measured by four indicators that described satisfaction with the neighborhood ('satisfied', 'average satisfaction', 'not satisfied') and perception of services in the area ('good', 'average', 'poor'). Social anchorage, defined as the level of ties with the neighborhood, was assessed using four indicators that described one's feeling of belonging ('yes', 'no'), knowing people in the area ('the majority', 'a substantial fraction', 'a few', 'no one'), feeling of safety walking at night ('very safe', 'safe', 'average safety', 'unsafe', 'very unsafe'), and exposure to assaults or harassments ('yes', 'no'). The social participation dimension was assessed by two items, namely belonging to a social/community group ('yes', 'no') and attending weekly religious gatherings ('always', 'some of the time', 'never'). Civic Trust, described as an acquired sense of confidence that emanates from respectful social interactions with others, was assessed in relation to the generalized trust in people in the area ('the majority', 'a substantial fraction', 'a few', 'no one'), trusting merchants ('the majority', 'a substantial fraction', 'a few', 'no one'), and vigilance being unnecessary when dealing with others ('yes', 'no'). Reciprocity, a measure of exchange of voluntary services with others, was assessed using two indicators, namely perception that a sense of reciprocity among community members prevails ('yes', 'no') and engagement in reciprocal exchange of favors with relatives, friends or neighbors in the month preceding the survey ('yes', 'no'). Hypothetical social support, a measure of the emotional and instrumental assistance available to the older adult, was assessed using four indicators inquiring about the self-perceived availability of someone to turn to in case of illness ('yes', 'no'), financial hardships ('yes, 'no'), personal hardships ('yes', 'no'), and when needing to go out ('yes', 'no'). Last, social network, a measure of the strength of social ties, was assessed based on the quality of the social interaction with children ('yes', 'no') and with relatives, friends, and neighbors ('yes', 'no'). 
In line with the literature (Nummela et al. 2009; Linden-Bostrom, Persson, and Eriksson 2010; Chemaitelly et al. 2013; Kawachi, Kennedy, and Glass 1999; Lindstrom, Sundquist, and Ostergren 2001), indicators describing the different subcomponents of the social capital construct were dichotomized using a conservative approach for combining negative outcomes. Favorable outcomes for each indicator were coded ' 1 ' while negative outcomes were coded ' 0 '. For example, for the 'satisfaction with the neighborhood' indicator, responses of 'satisfied' and 'average satisfaction' were coded 1 and those of 'not satisfied' were coded 0 ; for the 'knowing people in the area' indicator, responses of 'the majority' and 'a substantial fraction' were coded 1 and those of 'a few' and 'no one' were coded 0 , and for the 'feeling of safety walking at night' indicator responses of 'very safe', 'safe', and 'average safety' were coded 1 and those of 'unsafe' and 'very unsafe' were coded 0 . The responses for the resulting dichotomous indicators were then summed up to generate a continuous composite score for social capital (range: 0-21; Cronbach's alpha: 0.61).

Economic security was assessed using seven indicators (Table 2): current employment ('yes', 'no'), a monthly income value exceeding the minimum wage in Lebanon ('yes', 'no'), having other sources of income from self or spouse ('yes', 'no'), not receiving monetary assistance from children ('yes', 'no'), charity ('yes', 'no'), or relatives ('yes', 'no'), and having no dependents ('yes', 'no') (Chemaitelly et al. 2013; Clark 2004; National Council on Aging date not known). Following the same methodology used to generate a composite score for social capital, the responses for these indicators were summed up to generate a continuous composite score for the economic security construct (range: 0-7, Cronbach's alpha: 0.56).

Several socio-demographic factors and health-related characteristics were assessed as covariates (Table 1). Socio-demographics included age ('60-64', ‘65-69’, ‘ $\geq 70$ ’), gender 
('male', 'female'), education ('any formal schooling', 'no formal schooling'; the majority of older adults had only basic reading and writing skills), marital status ('married', 'not married'), history of displacement ('yes', 'no'), and number of years lived in the neighborhood. Co-morbidity was measured using self-reported physiciandiagnosed chronic medical conditions including hypertension, diabetes, cardiovascular and cerebrovascular diseases, arteriosclerosis problems, renal problems, and cancer. Each of these reported medical conditions was dichotomized and coded ' 1 ' whenever the condition was present and ' 0 ' otherwise. A summative score for chronic conditions was subsequently formed. We further characterized the physical health status of older adults based on limitations in activities of daily living ('yes', 'no') as measured using the Katz's ADL index (Katz et al. 1970). The latter assesses independence in six functions including bathing ('yes', 'no'), dressing up ('yes', 'no'), toileting ('yes', 'no'), transferring ('yes', 'no'), continence ('yes', 'no'), and feeding ('yes', ‘no’). An older adult reporting a limitation in any of these functions was considered as having a disability. Cigarettes and/or narghile smoking were also reported ('yes', 'no').

\section{Statistical analysis}

Bivariate analyses using $\mathrm{Chi}^{2}$ and ANOVA tests were performed to examine differentials in SRH across the three communities, Nabaa, Hey El-Sellom and Burj ElBarajneh camp, and further characterize them based on the socio-demographic and health profile of their older adults' population (Table 1). Cross-community comparisons in relation to social capital and economic security indicators and their summative scores were also performed using respectively, $\mathrm{Chi}^{2}$ and ANOVA tests (Table 2), as well as bivariate logistic and linear regression analyses (Table S1 in Supplementary Online Material; SOM). 
Four multivariate ordinal logistic regression models were subsequently developed to explain the perception of poorer SRH expressed by older adults in Hey ElSellom and in Burj El-Barajneh camp compared to those in Nabaa (Table 3). The first model examined the association between community and poorer SRH adjusting for the effect of socio-demographic and health-related factors that were either identified as significant in the bivariate analysis (Table 1) or known as established correlates of poor SRH. Models 2 and 3 assessed, respectively, the individual contribution of each of the economic security and social capital constructs to the association between community and poorer SRH net of the effect of socio-demographic and health-related factors. The relative contribution of the economic security and social capital constructs (incorporated simultaneously in the model) was assessed in Model 4. To examine the magnitude of the differences between Hey El-Sellom and Burj El-Barajneh with respect to poorer SRH, supplemental multivariate ordinal logistic regression analyses were performed applying the models described above while using Burj El-Barajneh as the reference community (Table S2 in SOM). The results of these multivariate analyses were reported using odds ratios (OR) and 95\% confidence intervals (CI). Sampling weights were applied to all analyses to adjust for cluster sampling effects and the unequal sampling probabilities from these neighborhoods. Statistical analyses were performed using STATA/SE version 13.0, and p-value $\leq 0.05$ was considered significant.

\section{Social capital and economic security: mediation tests}

Analyses testing whether the social capital and economic security constructs will qualify as mediators for the association between community and SRH based on Baron and Kenny's criteria were also performed (Baron and Kenny 1986). These 
entailed testing whether a) the type of neighborhood is significantly associated with each of the social capital and economic security constructs (Table 2 and Table S1 in SOM), b) the social capital and economic security constructs are significantly associated with poorer SRH (data not shown), and c) the type of neighborhood is significantly associated with poorer SRH, and this association becomes attenuated towards the null hypothesis and not significant after controlling for social capital and economic security constructs (Table 3).

\section{Sensitivity analyses}

A sensitivity analysis was performed to assess the robustness of our findings to the use of a trichotomous measure for SRH instead of the original 5-point likert scale for that measure. To this end, we applied our full multivariate ordinal logistic regression model adjusted for the effects of the socio-demographic, health, economic security and social capital variables (Model 4) to the association between community and poorer SRH using respectively, the trichotomous and the 5-point likert scale measures (Table S3 in SOM).

Another sensitivity analysis was implemented to assess the robustness of our findings to an alternative conceptualization of social capital that distinguishes between communityand individual-level resources (Table S4 in SOM). A composite score for each of the community- and individual-level social capital measures was calculated by summing up their respective dichotomous indicators. The contribution of the resulting measures to the association between community and poorer SRH was subsequently evaluated using the multivariate ordinal linear regression analyses, described earlier (Table S5 in SOM). 


\section{Results}

Significant differences in SRH were observed across the three communities (Table 1). Nabaa had the highest proportion of older adults reporting good SRH (41.5\%), followed by Hey El-Sellom (33.3\%) and Burj El-Barajneh (25.2\%). The distribution of average and poor SRH was, respectively, $37.0 \%$ and $21.5 \%$ in Nabaa, $23.9 \%$ and $42.7 \%$ in Hey El-Sellom, and 31.3\% and 43.5\% in Burj El-Barajneh camp. The three communities were comparable in terms of age, gender and marital status distributions. Older adults in Nabaa were significantly more likely to have achieved formal schooling (48.4\%) than their counterparts in Hey El-Sellom (23.7\%) and Burj El-Barajneh (39.4\%). More than two thirds of the older adult population across these settings reported a history of displacement (69.3\%) with the highest percentage being noted in Burj El-Barajneh $(83.2 \%)$. The overall mean number of years lived in the household $( \pm \mathrm{SD})$ at the time of the survey was $26.5( \pm 16.2)$ years with significant differences across the three communities, being highest in Burj El-Barajneh camp (35.3 years), followed by Nabaa (23.8 years), and Hey El-Sellom (17.4 years). Close to $70 \%$ of older adults reported being diagnosed with at least one chronic medical condition, and around one third faced limitations in their activities of daily living. The latter was significantly highest in Burj El-Barajneh camp $(53.5 \%, \mathrm{p}<0.001)$. Tobacco smoking was also more prevalent in Burj El-Barajneh camp (36.6\%) than in Nabaa (26.1\%) and Hey El-Sellom (22.0\%).

\section{[TABLE 1 ABOUT HERE]}

Table 2 shows the distribution of social capital and economic security indicators compared across the three communities. Overall, Nabaa had the highest level of social capital, showing on a 21-points score, a mean of 13.5, while Burj El-Barajneh camp and Hey El-Sellom followed with mean scores of 12.1 and 10.6, respectively $\left(F_{2,733}=52.51\right.$, p-value $<0.001)$. The higher levels of social capital observed in Nabaa was mainly 
attributed to consistently higher scores on locational capital, social participation, reciprocity, hypothetical social support, and social networks beyond the immediate family. However, Burj El-Barajneh camp appeared to match and, in some instances, exceed Nabaa and Hey El-Sellom in relation to certain other social capital indicators such as social anchorage and civic trust. For example, $86.2 \%$ of older adults in Burj ElBarajneh expressed strong feelings of belonging to the community compared to $74.6 \%$ in Hey El-Sellom and 51.9\% in Nabaa. Also, stronger feelings of civic trust towards merchants and community members prevailed in Burj El-Barajneh camp (67.9\% and $27.2 \%$, respectively) compared to Nabaa (49.7\% and $21.0 \%$, respectively) and Hey ElSellom (56.4\% and 7.6\%, respectively). Hey El-Sellom scored lowest on indicators for hypothetical social support with only about two third of older adults reporting that they can turn to someone in case of financial hardships or when in need of help with personal hardships, and slightly more than half reporting that they can turn to someone when they feel like going out. Meanwhile, the vast majority of older adults across the three communities reported having strong social networks and excellent relations with their children, relatives, friends, and neighbors.

In contrast to the above, in examining differentials in economic security across the three communities, Burj El-Barajneh camp was found to be the most disadvantaged (Table 2), while Nabaa and Hey El-Sellom exhibited comparable characteristics. On a 7-points score, we estimated a mean economic security of 2.9 in Burj El-Barajneh compared to 4.0 in Nabaa and 4.1 in Hey El-Sellom $\left(F_{2,736}=69.86\right.$, p-value $\left.<0.001\right)$. Significant differences in economic security were revealed between Burj El-Barajneh camp and each of Nabaa and Hey El-Sellom. Meanwhile, Nabaa and Hey El-Sellom had comparable economic profiles. Indeed, although levels of current employment were not significantly different across the three communities (17\% overall), older adults in Nabaa 
and Hey El-Sellom were significantly more likely to have a monthly earning exceeding the minimum wage than those in Burj El-Barajneh camp $(84.6 \%$ and $79.7 \%$ vs. $46.8 \%$, respectively, $\mathrm{p}<0.001)$. Older adults in Burj El-Barajneh were also more likely than those in the other two communities to be dependent on others, thus receiving income assistance from charity ( $52.0 \%$ vs. $4.8 \%$ and $1.7 \%$, respectively, p-value <0.001) and were more likely to financially support other dependents $(68.3 \%$ vs. $42.5 \%$ and $41.5 \%$, respectively, p-value $<0.001)$.

\section{[TABLE 2 ABOUT HERE]}

Table S1 in SOM shows findings of the bivariate regression analyses examining the magnitude of the association between the three communities and the various social capital and economic security indicators as well as their summative scores. Compared to Nabaa, older adults in Hey El-Sellom and Burj El-Barajneh were significantly less likely to exhibit neighborhood satisfaction, engage in social activities or reciprocal exchange of non-financial favors, or to have social support. This translated to older adults in Hey El-Sellom and Burj El-Barajneh being significantly more likely to have lower scores on the social capital construct than older adults in Nabaa $(\beta=-2.90,95 \%$ CI: $-3.48 ;-2.31$ and $\beta=-1.45,95 \%$ CI: $-1.90 ;-0.98$, respectively). As expected, older adults in Burj El-Barajneh camp were particularly prone for poorer socio-economic security compared to those in Nabaa $(\beta=-1.12,95 \%$ CI: $-1.33 ;-0.92)$. Meanwhile, there was no difference in economic security between older adults residing in Hey El-Sellom and those residing in Nabaa $(\beta=0.12,95 \% \mathrm{CI}:-0.14 ; 0.38)$.

Compared to Burj El-Barajneh, older adults in Hey El-Sellom were significantly more likely to be satisfied with their neighborhood, but less likely to express feelings of social anchorage and civic trust, to be socially active, and to have someone to turn to in case of illness or when feeling like going out. Meanwhile, there was no difference between the 
two neighborhoods with respect to perception of local infrastructure, feeling safe to walk at night, engaging in reciprocal exchange of services, getting support in case of financial and personal hardship, and having a strong social network. However, overall, older adults in Hey El-Sellom were significantly more likely to have a lower social capital score than those in Burj El-Barajneh camp ( $\beta=-1.45,95 \%$ CI: -2.07; -0.82). Lebanese older adults in Nabaa and Hey El-Sellom were also significantly more likely to score higher on the economic security construct than their Palestinian counterparts in the camp ( $\beta=1.12,95 \%$ CI: $0.92 ; 1.33$ and $\beta=1.25,95 \%$ CI: $0.97 ; 1.53$, respectively). Findings of our multivariate regression analyses are presented in Table 3. Older adults residing in Hey El-Sellom and Burj El-Barajneh had higher odds for reporting poorer SRH outcomes (OR: 2.07, 95\% CI: 1.36-3.16 in Hey El Sellom and OR: 1.72, 95\% CI: 1.19-2.49 in Burj El-Barajneh) than older adults residing in Nabaa in the first model adjusted for socio-demographic and health-related factors (Model 1). The inclusion of the economic security score in Model 2 explained the variation in poorer SRH for Burj El-Barajneh where the OR was attenuated from 1.72 (95\% CI: $1.19-2.49)$ to 1.42 (95\% CI: 0.96-2.08) after adjusting for confounders but not for Hey El-Sellom (OR: 2.12, 95\% CI: 1.39-3.24 in Model 1 vs. OR: 2.12, 95\% CI: 1.39-3.24 in Model 2). However, unlike Model 2, the multivariate model assessing the contribution of social capital (Model 3) was able to explain most of the variation in poorer SRH for older adults in both Hey El-Sellom (OR: 1.46, 95\% CI: 0.94-2.23) and Burj El-Barajneh (OR: 1.45, 95\% CI: 1.00-2.12). In the fully adjusted model (Model 4) examining the relative contribution of the social capital and economic security constructs, further reduction of the OR for only Burj El-Barajneh camp to 1.18 (95\% CI: 0.80-1.76) was noted.

[TABLE 3 ABOUT HERE] 
Our supplemental multivariate regression analyses using Burj El-Barajneh as a reference, showed no significant differences in poorer SRH between Hey El-Sellom and Burj El-Barajneh camp in the first model controlling for basic socio-demographic and health variables (OR: 1.20, 95\% CI: 0.73-1.96), nor in subsequent models controlling for additional covariates (Table S2 in SOM).

\section{Mediation analysis}

Our analyses assessing whether the social capital and economic security constructs fulfill Baron and Kenny's mediation criteria (Baron and Kenny 1986) revealed significant associations between the type of neighborhood and each of the social capital and economic security constructs (Table 2 and Table S1 in SOM). The social capital and economic security constructs were also significantly associated with poorer SRH (OR: 0.84, 95\% CI: 0.81-0.89 and OR: 0.70, 95\% CI: 0.63-0.78, respectively; bivariate analyses that are not shown in tables). In addition, the significant association between type of neighborhood and poorer SRH (Tables 1 and 3) was rendered non-significant after the inclusion of the social capital and economic security constructs (Table 3). These analyses affirm the social capital and economic security constructs as mediators for the association between type of neighborhood and poorer SRH.

\section{Sensitivity analyses}

Our sensitivity analysis comparing the outcomes of multivariate ordinal regression analyses (Model 4) using respectively, the 3-point and 5-point measures for poorer SRH yielded similar results with a slightly better $\mathrm{R}^{2}$ for the model using the trichotomized outcome (Table S3 in SOM).

We explored the robustness of our findings to an alternative conceptualization of social capital that distinguishes between community- and individual-level resources (Table S4 
in SOM). On an 8-point score for community-level social capital, Nabaa showed a mean of 5.4, followed by Burj El-Barajneh camp with a mean of 4.2, and Hey El-Sellom with a mean of 4.1. Similarly, on a 13-point score for individual-level social capital, Nabaa had a higher score (mean of 8.1), than Burj El-Barajneh (mean of 7.8), and Hey ElSellom (mean of 6.5). Incorporating community-level social capital in a multivariate ordinal regression model reduced the magnitude of the association between community and poorer SRH from an OR of 2.07 (95\% CI: 1.36-3.16) to 1.59 (95\% CI: 0.94-2.23) in Hey El-Sellom and from 1.72 (95\% CI: 1.20-2.49) to 1.35 (95\% CI: 1.00-2.12) in Burj El-Barajneh camp, after controlling for socio-demographic and health variables (Table S5 in SOM). On the other hand, while it reduced the magnitude of the association between community and poorer SRH, a model incorporating individual-level social capital did not fully explain this association among older adults in Hey El-Sellom (OR: 1.71; 95\% CI: 1.11-2.64). This model did not also have an impact on the association between Burj El-Barajneh and poorer SRH (OR: 1.70; 95\% CI: 1.18-2.46). However, all three constructs for economic security, community-level and individual-level social capital remained significant in the full multivariate ordinal logistic model examining the magnitude of the association between community and poorer SRH. The latter was assessed at an OR of 1.48 (95\% CI: 0.96-2.32) in Hey El-Sellom and of 1.16 (95\% CI: 0.80-1.76) in Burj El-Barajneh camp compared to Nabaa.

\section{Discussion}

This study extends on previous research on the various roles played by social capital and economic security in explaining health disparities among older adults within the context of ethnically-diverse underprivileged urban neighborhoods. As a result of years of civil strife and conflict in Lebanon, the three communities examined in this study 
share a low socio-economic profile characterized by dense urban livings, economic hardships, displacement, and lack of public services and infrastructure. Despite these similarities, striking differences in SRH were revealed and these were explained by differentials in the availability of social and economic resources-possibly a reflection of the structural differences across these communities. Older adults in Nabaa, a formal neighborhood, fared better in SRH than the older cohort in Hey El-Sellom, an informal settlement, and the Palestinian refugees in Burj El-Barajneh camp. Although older adults in Nabaa and Hey El-Sellom were similar with regard to economic security, Nabaa exhibited higher levels of social capital. Social and economic deficiencies appeared to contribute equally to the poorer perception of health among older adults in Burj El-Barajneh camp. Meanwhile, the poorer SRH among older adults in Hey ElSellom was largely determined by the lower levels of social capital in this neighborhood. These findings and the contextual realizations of these relations are discussed below.

The disparity in SRH between older adults in Burj El-Barajneh camp and Nabaa is not surprising. Palestinian camps in Lebanon were established as temporary settlements following the 1948 Palestinian exodus, and political agreements entailed that the Lebanese government has minimal interference in the camps' governance. Six decades past their institution, the camps are still viewed as temporary arrangements and are often overlooked in the government's infrastructure renovation plans (Makhoul, Ghanem, and Ghanem 2003). Calls for granting citizenship to the second- and thirdgeneration Lebanese-born Palestinians have been continuously rejected out of concerns over upsetting the sectarian balance in the country (Abdulrahim and Khawaja 2011). Palestinians' participation in the Lebanese labor force is also largely restricted leading those working in professional jobs to earn substantially lower wages than their 
Lebanese counterparts (Abdulrahim and Khawaja 2011). The lack of adequate social and economic integration programs for Palestinian refugees makes Burj El-Barajneh camp the most deprived among the three neighborhoods. This disconnect may have fostered social ties within the camp and may have led to higher levels of social support and social anchorage among its residents, despite poor locational capital and the absence of proper national integration schemes. The environmental and economic disparities between Palestinian older refugees and Lebanese older adults were also reflected in health differentials, with Palestinians bearing twice the disability burden and significantly higher smoking levels. Our analysis underscored the role of social capital and economic resources in shaping poor SRH among Palestinian older adults. These findings appear to be consistent with reviews and studies conducted among underprivileged refugees and ethnic minorities elsewhere. Research from Europe and the USA argues that disparities in health, including a lower perception of health, are a direct outcome of the disadvantage triad of poor sense of control, social isolation, and deprivation (Lindstrom, Sundquist, and Ostergren 2001; Nielsen and Krasnik 2010; Wong et al. 2011).

Our findings of a significant differential in SRH between Hey El-Sellom and the baseline Nabaa community, largely explained by social capital, merits further discussion of the contextual factors specific to Hey El-Sellom. Although Lebanese, residents of these communities have different displacement histories and their social conditions and health are shaped by differences in background and culture. Residents of Hey El-Sellom are, in the majority, displaced from rural areas in the South of Lebanon, which is perceived as their primary place of belonging (Makhoul, Ghanem, and Ghanem 2003). Because support systems in Lebanon, as elsewhere in Arab countries, tend to revolve around the extended family sphere (Rashad, Osman, and Roudi-Fahimi 
2005; Sibai and Yamout 2012), older persons compelled to remain in urban settlements may find themselves disconnected from their origin and from extended familial social networks (Habib et al. 2011; Connidis 2009) and, hence, prone to poorer health. This social disconnect was evident, particularly, through the low levels of social participation, support, trust, and reciprocity in Hey El-Sellom (Table 2 and Table S1 in SOM). Older adults displaced from rural areas may also be facing challenges in adjusting to urban living. Indeed, unlike urban areas, villages tend be less crowded, have more friendly physical environments for elder adults, a slower pace of life, and multiple opportunities for vibrant social interactions among residents. The nature of informal settlements could have also added other constraints on the involvement of older adults residing in these neighborhoods in decision-making at community level, thus contributing to their poor SRH. For instance, electoral rights in Lebanon are defined by the individual's area of origin rather than area of residence, which may have contributed to the weakened local ties and a detachment from community affairs in Hey El-Sellom. These observations were affirmed by our regression analyses emphasizing social capital as a key determinant of well-being among older adults even after controlling for economic deprivation (Table 3).

We observed no difference between older adults in Hey El-Sellom and those in Burj ElBarajneh camp with respect to poorer SRH (Table S2 in SOM). One plausible explanation to our findings pertains to the type of migration-a factor closely related to self-perceived health (Sundquist, Johansson, and Sundquist 2009; Sundquist et al. 2000). Indeed, unlike Nabaa where older adults tend to be voluntary-returns to their community post-war, the settlement of older adults in Hey El-Sellom and Burj ElBarajneh camp was rather involuntary. The context in which these displacements occurred and the resulting sensitivities between the various ethnicities dictated that 
individuals displaced from southern villages reside in informal settlements in the southern suburbs of Beirut and that Palestinian refugees be confined to their camps. Evidence has linked 'forced' migration/displacement and the associated sense of lack of control to poorer health outcomes and poorer SRH (Sundquist, Johansson, and Sundquist 2009; Sundquist et al. 2000). However, further research is warranted to explore whether there could be other explanations to the observed trend.

Our alternative conceptualization of the social capital construct highlighted the role of community-level resources in alleviating poorer SRH among older adults and indicated that, despite their importance, individual-level resources are not the sole determinants of older adults' well-being (Table S5 in SOM). These findings are in line with an abundant literature on 'Ageing in Place' which highlights the sense of attachment, security, and feelings of autonomy that older adults tend to attribute to their neighborhoods and the health benefits associated with a positive neighborhood perception (Wiles et al. 2012; Wiles et al. 2009). Our findings emphasize the need to advocate for infrastructure development plans that would maximize the opportunities of older adults in underserved communities to carry comfortably their activities of daily living, engage in ageappropriate recreational activities, promote their social interaction, and provide them with a positive perception of their physical environment.

Our study findings need to be discussed in view of certain limitations. The crosssectional design of the survey renders the temporal evolution of events less evident. For instance, while low levels of social capital and economic security may have likely contributed to poorer SRH among older adults, there is a possibility that poorer SRH could have affected not only social capital pillars, but also the motivation to engage in income generating activities. Furthermore, in the absence of a unique standardized scale for social capital, our constructs' indicators were adapted from scales that have been 
widely used in Western countries. The authenticity of these indicators to the original measures and their applicability to the Arab context still need to be established using validation studies. Also, our analytical approach was limited by the various metrics used to assess the indicators of the social capital and economic security constructs. This dictated the dichotomization of measures prior to constructs' development which may have obscured part of the variability captured by those measures, thus possibly introducing bias to these constructs. A formal mediational analysis for the social capital and economic security constructs was also not possible given the ordinal nature of our dependent variable. Finally, it should be mentioned that, although the findings of this study provide insights into possible determinants of SRH among older adults, they may not be directly generalizable to older adults in other impoverished settings or to the older Lebanese population at large.

Since the date of this survey, the country has witnessed several other conflicts, including the July 2006 war on Lebanon and the more recent Syrian crisis, yielding an influx of over 1.5 million refugees. The resulting strains on existing social and economic infrastructures in these neighborhoods are magnified by the prevailing governmental dysfunction hindering the development and implementation of interventions. While these emerging circumstances could have an impact on the magnitude of the association between social and economic constructs and SRH, they are unlikely to change the directionality of our findings highlighting the importance of these dimensions for well-being at old age.

In conclusion, this study sheds light on the role of social capital and economic security in explaining disparities in SRH among older adults in marginalized communities. Programs and policy should focus on addressing these, often overlooked, dimensions of well-being among older adults especially in post-conflict regions. This is a timely public 
health concern in the Arab region in light of the ongoing regional strives and the increasing numbers of displaced communities with various geo-historical trajectories of movements and displacements. 


\section{References}

Abdulrahim, S., and K. El Asmar. 2012. "Is self-rated health a valid measure to use in social inequities and health research? Evidence from the PAPFAM women's data in six Arab countries." Review of. Int J Equity Health 11:53. doi: 10.1186/1475-9276-11-53.

Abdulrahim, S., and M. Khawaja. 2011. "The cost of being Palestinian in Lebanon." Review of. Journal of Ethnic and Migration Studies 37 (1):151-66.

Ahmad, B., V. Ryan, W. Maziak, T. Pless-Mulloli, and M. White. 2013. "The influence of neighbourhood formality status and socio-economic position on self-rated health among adult men and women: a multilevel, cross sectional, population study from Aleppo, Syria." Review of. BMC Public Health 13:233. doi: 10.1186/1471-2458-13-233.

Baron, R. M., and D. A. Kenny. 1986. "The moderator-mediator variable distinction in social psychological research: conceptual, strategic, and statistical considerations." Review of. J Pers Soc Psychol 51 (6):1173-82.

Berkman, L. F. 2000. "Social support, social networks, social cohesion and health." Review of. Soc Work Health Care 31 (2):3-14. doi: 10.1300/J010v31n02_02.

Berkman, L. F., L. Leo-Summers, and R. I. Horwitz. 1992. "Emotional support and survival after myocardial infarction. A prospective, population-based study of the elderly." Review of. Ann Intern Med 117 (12):1003-9.

Bloom, D. E., S. Chatterji, P. Kowal, P. Lloyd-Sherlock, M. McKee, B. Rechel, L. Rosenberg, and J. P. Smith. 2015. "Macroeconomic implications of population ageing and selected policy responses." Review of. Lancet 385 (9968):649-57. doi: 10.1016/S0140-6736(14)61464-1.

Carpiano, R. M. 2006. "Toward a neighborhood resource-based theory of social capital for health: can Bourdieu and sociology help?" Review of. Soc Sci Med 62 (1):165-75. doi: 10.1016/j.socscimed.2005.05.020.

Chemaitelly, H., C. Kanaan, H. Beydoun, M. Chaaya, M. Kanaan, and A. M. Sibai. 2013. "The role of gender in the association of social capital, social support, and economic security with self-rated health among older adults in deprived communities in Beirut." Review of. Qual Life Res 22 (6):1371-9. doi: 10.1007/s11136-012-0273-9.

Chen, X., P. Wang, R. Wegner, J. Gong, X. Fang, and L. Kaljee. 2015. "Measuring Social Capital Investment: Scale Development and Examination of Links to Social Capital and Perceived Stress." Review of. Soc Indic Res 120 (3):669-87. doi: 10.1007/s11205-014-0611-0.

Clark, Robert L. 2004. The economics of an aging society. Malden, MA: Blackwell.

Connidis, Ingrid Arnet. 2009. Family ties and aging: Pine Forge Press.

DeSalvo, K. B., N. Bloser, K. Reynolds, J. He, and P. Muntner. 2006. "Mortality prediction with a single general self-rated health question. A meta-analysis." Review of. J Gen Intern Med 21 (3):267-75. doi: 10.1111/j.15251497.2005.00291.x.

Eriksson, M. 2011. "Social capital and health--implications for health promotion." Review of. Glob Health Action 4:5611. doi: 10.3402/gha.v4i0.5611.

Grundy, E., and A. Sloggett. 2003. "Health inequalities in the older population: the role of personal capital, social resources and socio-economic circumstances." Review of. Soc Sci Med 56 (5):935-47. 
Habib, R. R., Z. Mahfoud, M. Fawaz, S. H. Basma, and J. S. Yeretzian. 2009. "Housing quality and ill health in a disadvantaged urban community." Review of. Public Health 123 (2):174-81. doi: 10.1016/j.puhe.2008.11.002.

Habib, R. R., N. Yassin, J. Ghanawi, P. Haddad, and Z. Mahfoud. 2011. "Double jeopardy: assessing the association between internal displacement, housing quality and chronic illness in a low-income neighborhood." Review of. $Z$ Gesundh Wiss 19 (2):171-82. doi: 10.1007/s10389-010-0368-0.

Habib, R. R., A. Zohry, I. Nuwayhid, and F. Najdi. 2006. "Older adults in the division of domestic labor in communities on the outskirts of Beirut." Review of. Eur J Ageing 3 (3):137-45. doi: 10.1007/s10433-006-0031-3.

Harpham, T., E. Grant, and E. Thomas. 2002. "Measuring social capital within health surveys: key issues." Review of. Health Policy Plan 17 (1):106-11.

Huisman, M., S. Read, C. A. Towriss, D. J. Deeg, and E. Grundy. 2013.

"Socioeconomic Inequalities in Mortality Rates in Old Age in the World Health Organization Europe Region." Review of. Epidemiol Rev. doi: 10.1093/epirev/mxs010.

Idler, E. L., and Y. Benyamini. 1997. "Self-rated health and mortality: a review of twenty-seven community studies." Review of. J Health Soc Behav 38 (1):21-37.

Jawad, M. H., A. M. Sibai, and M. Chaaya. 2009. "Stressful life events and depressive symptoms in a post-war context: which informal support makes a difference?" Review of. J Cross Cult Gerontol 24 (1):19-32. doi: 10.1007/s10823-008-90595.

Jylha, M. 2009. "What is self-rated health and why does it predict mortality? Towards a unified conceptual model." Review of. Soc Sci Med 69 (3):307-16. doi: 10.1016/j.socscimed.2009.05.013.

Katz, S., T. D. Downs, H. R. Cash, and R. C. Grotz. 1970. "Progress in development of the index of ADL." Review of. Gerontologist 10 (1):20-30.

Kawachi, I., B. P. Kennedy, and R. Glass. 1999. "Social capital and self-rated health: a contextual analysis." Review of. Am J Public Health 89 (8):1187-93.

Kawachi, I., B. P. Kennedy, K. Lochner, and D. Prothrow-Stith. 1997. "Social capital, income inequality, and mortality." Review of. Am J Public Health 87 (9):14918.

Kawachi, I., S. V. Subramanian, and N. Almeida-Filho. 2002. "A glossary for health inequalities." Review of. J Epidemiol Community Health 56 (9):647-52.

Kawachi, I., S.V. Subramanian, and D. Kim. 2008. Social capital and health. New York: Springer.

Khawaja, M., S. Abdulrahim, R. A. Soweid, and D. Karam. 2006. "Distrust, social fragmentation and adolescents' health in the outer city: Beirut and beyond." Review of. Soc Sci Med 63 (5):1304-15. doi: 10.1016/j.socscimed.2006.03.047.

Khawaja, M., and M. Mowafi. 2006. "Cultural capital and self-rated health in low income women: evidence from the Urban Health Study, Beirut, Lebanon." Review of. J Urban Health 83 (3):444-58. doi: 10.1007/s11524-006-9051-8.

Kim, D., and I. Kawachi. 2006. "A multilevel analysis of key forms of community- and individual-level social capital as predictors of self-rated health in the United States." Review of. J Urban Health 83 (5):813-26. doi: 10.1007/s11524-0069082-1.

Linden-Bostrom, M., C. Persson, and C. Eriksson. 2010. "Neighbourhood characteristics, social capital and self-rated health--a population-based survey in Sweden." Review of. BMC Public Health 10:628. doi: 10.1186/1471-2458-10628. 
Lindstrom, M., J. Sundquist, and P. O. Ostergren. 2001. "Ethnic differences in self reported health in Malmo in southern Sweden." Review of. J Epidemiol Community Health 55 (2):97-103.

Makhoul J. 2003. "Physical and social contexts of the three urban communities of Nabaa, Borj el Barajneh Palestinian camp, and Hay el-Sullom.Unpublished memo." In. Beirut: Center for Research on Population and Health, American University of Beirut.

Makhoul, J., D. A. Ghanem, and M. Ghanem. 2003. "An ethnographic study of the consequences of social and structural forces on children: the case of two lowincome Beirut suburbs." Review of. Environment and Urbanization 15 (2):24959. doi: Doi 10.1177/095624780301500213.

Mavaddat, N., R. A. Parker, S. Sanderson, J. Mant, and A. L. Kinmonth. 2014. "Relationship of self-rated health with fatal and non-fatal outcomes in cardiovascular disease: a systematic review and meta-analysis." Review of. PLoS One 9 (7):e103509. doi: 10.1371/journal.pone.0103509.

Mavaddat, N., J. M. Valderas, R. van der Linde, K. T. Khaw, and A. L. Kinmonth. 2014. "Association of self-rated health with multimorbidity, chronic disease and psychosocial factors in a large middle-aged and older cohort from general practice: a cross-sectional study." Review of. BMC Fam Pract 15:185. doi: 10.1186/s12875-014-0185-6.

Mellor, J. M., and J. Milyo. 2005. "State social capital and individual health status." Review of. J Health Polit Policy Law 30 (6):1101-30. doi: 10.1215/0361687830-6-1101.

National Council on Aging. "Economic security for seniors: fact sheet." Accessed September 15, 2014. https://www.ncoa.org/news/resources-for-reporters/get-thefacts/economic-security-facts/.

Nielsen, S. S., and A. Krasnik. 2010. "Poorer self-perceived health among migrants and ethnic minorities versus the majority population in Europe: a systematic review." Review of. Int J Public Health 55 (5):357-71. doi: 10.1007/s00038010-0145-4.

Nummela, O., T. Sulander, A. Karisto, and A. Uutela. 2009. "Self-rated health and social capital among aging people across the urban-rural dimension." Review of. Int J Behav Med 16 (2):189-94. doi: 10.1007/s12529-008-9027-z.

Pollack, C. E., and O. von dem Knesebeck. 2004. "Social capital and health among the aged: comparisons between the United States and Germany." Review of. Health Place 10 (4):383-91. doi: 10.1016/j.healthplace.2004.08.008.

Rashad, Hoda, Magued Osman, and Farzaneh Roudi-Fahimi. 2005. Marriage in the Arab World: Population Reference Bureau (PRB). http://www.igwg.org/pdf05/MarriageInArabWorld_Eng.pdf.

Sibai, A. M., and R. Yamout. 2012. "Family-based old age care in Arab countries: Between tradition and modernity." In Population dynamics in Muslim countries, edited by Groth H. and A. Sousa-Poza, 63-76. New York: Springer.

Smith, J. P. 1999. "Healthy bodies and thick wallets: the dual relation between health and economic status." Review of. J Econ Perspect 13 (2):144-66.

Stenholm, S., M. Kivimaki, M. Jylha, I. Kawachi, H. Westerlund, J. Pentti, M. Goldberg, M. Zins, and J. Vahtera. 2015. "Trajectories of self-rated health in the last 15 years of life by cause of death." Review of. Eur J Epidemiol. doi: 10.1007/s10654-015-0071-0. 
Subramanian, S. V., D. J. Kim, and I. Kawachi. 2002. "Social trust and self-rated health in US communities: a multilevel analysis." Review of. J Urban Health 79 (4 Suppl 1):S21-34.

Subramanian, S. V., D. Kim, and I. Kawachi. 2005. "Covariation in the socioeconomic determinants of self rated health and happiness: a multivariate multilevel analysis of individuals and communities in the USA." Review of. $J$ Epidemiol Community Health 59 (8):664-9. doi: 10.1136/jech.2004.025742.

Subramanyam, M., I. Kawachi, L. Berkman, and S. V. Subramanian. 2009. "Relative deprivation in income and self-rated health in the United States." Review of. Soc Sci Med 69 (3):327-34. doi: 10.1016/j.socscimed.2009.06.008.

Sundquist, J., L. Bayard-Burfield, L. M. Johansson, and S. E. Johansson. 2000. "Impact of ethnicity, violence and acculturation on displaced migrants: psychological distress and psychosomatic complaints among refugees in Sweden." Review of. J Nerv Ment Dis 188 (6):357-65.

Sundquist, Jan, Sven-Erik Johansson, and Kristina Sundquist. 2009. "The influence of age at migration and length of residence on self-rated health among Swedish immigrants: a cross-sectional study." Review of. Ethnicity \& Health 14 (1):13p. doi: 10.1080/13557850802345973.

Travis, L. A., J. M. Lyness, C. G. Shields, D. A. King, and C. Cox. 2004. "Social support, depression, and functional disability in older adult primary-care patients." Review of. Am J Geriatr Psychiatry 12 (3):265-71.

United Nations Population Division. "World Urbanization Prospects, the 2011 Revision." Accessed September 22, 2014. http://esa.un.org/unup/Countryprofiles/country-profiles_1.htm.

. "World Population Prospects, the 2012 Revision." Accessed September 22, 2014. http://esa.un.org/unpd/wpp/.

Webster, N. J., T. C. Antonucci, K. J. Ajrouch, and S. Abdulrahim. 2015. "Social networks and health among older adults in Lebanon: the mediating role of support and trust." Review of. J Gerontol B Psychol Sci Soc Sci 70 (1):155-66. doi: 10.1093/geronb/gbu149.

Wen, L. M., C. Rissel, A. Voukelatos, and P. Sainsbury. 2003. "Community involvement and self-rated health status: findings from a cross-sectional survey in Central Sydney." Review of. N S W Public Health Bull 14 (11-12):213-7.

Wiles, J. L., R. E. Allen, A. J. Palmer, K. J. Hayman, S. Keeling, and N. Kerse. 2009. "Older people and their social spaces: a study of well-being and attachment to place in Aotearoa New Zealand." Review of. Soc Sci Med 68 (4):664-71. doi: 10.1016/j.socscimed.2008.11.030.

Wiles, J. L., A. Leibing, N. Guberman, J. Reeve, and R. E. Allen. 2012. "The meaning of "aging in place" to older people." Review of. Gerontologist 52 (3):357-66. doi: 10.1093/geront/gnr098.

Wong, E. C., G. N. Marshall, T. L. Schell, M. N. Elliott, S. H. Babey, and K. Hambarsoomians. 2011. "The unusually poor physical health status of Cambodian refugees two decades after resettlement." Review of. J Immigr Minor Health 13 (5):876-82. doi: 10.1007/s10903-010-9392-y.

World Health Organization. 2007. "Global age-friendly cities: A guide." In. France: World Health Organization. 
Table 1. Socio-demographic and health-related characteristics of older adults, Urban Health Survey, Beirut, 2003.

Table 2. Comparison of social capital and economic security indicators across Nabaa, Hey El-Sellom, and Burj El-Barajneh camp, Urban Health Study, Beirut, 2003.

Table 3. Multivariate ordinal logistic regression analyses for poorer self-rated health, Urban Health Study, Beirut, 2003. 
TABLE 1 Socio-demographic and health-related characteristics of older adults, Urban Health Survey, Beirut, 2003.

\begin{tabular}{|c|c|c|c|c|c|c|c|c|c|}
\hline \multirow{3}{*}{ Variables } & \multicolumn{2}{|c|}{ Total } & \multicolumn{2}{|c|}{ Nabaa } & \multicolumn{2}{|c|}{ Hey El-Sellom } & \multicolumn{2}{|c|}{$\begin{array}{l}\text { Burj El-Barajneh } \\
\text { Camp }\end{array}$} & \multirow{3}{*}{$p$-value } \\
\hline & \multicolumn{2}{|c|}{$N=740$} & \multicolumn{2}{|c|}{$N=376$} & \multicolumn{2}{|c|}{$N=118$} & \multicolumn{2}{|c|}{$N=246$} & \\
\hline & $n$ & $\%$ & $n$ & $\%$ & $n$ & $\%$ & $n$ & $\%$ & \\
\hline \multicolumn{10}{|l|}{ Self-rated health } \\
\hline Good and better & 257 & 34.8 & 156 & 41.5 & 39 & 33.3 & 62 & 25.2 & $<0.001$ \\
\hline Average & 244 & 33.0 & 139 & 37.0 & 28 & 23.9 & 77 & 31.3 & \\
\hline Poor and worse & 238 & 32.2 & 81 & 21.5 & 50 & 42.7 & 107 & 43.5 & \\
\hline \multicolumn{10}{|l|}{ Socio-demographic } \\
\hline \multicolumn{10}{|l|}{ Age (years) } \\
\hline $60-64$ & 260 & 35.1 & 114 & 30.3 & 47 & 39.8 & 99 & 40.2 & 0.088 \\
\hline $65-69$ & 211 & 28.5 & 118 & 31.4 & 31 & 26.3 & 62 & 25.2 & \\
\hline$\geq 70$ & 269 & 36.4 & 144 & 38.3 & 40 & 33.9 & 85 & 34.6 & \\
\hline Sex (\% males) & 328 & 44.3 & 165 & 43.9 & 50 & 42.4 & 113 & 45.9 & 0.790 \\
\hline Marital status (\% married) & 462 & 62.4 & 239 & 63.6 & 72 & 61.0 & 151 & 61.4 & 0.810 \\
\hline Education (\% any formal schooling) & 307 & 41.5 & 182 & 48.4 & 28 & 23.7 & 97 & 39.4 & $<0.001$ \\
\hline History of displacement (\% yes) & 510 & 69.3 & 223 & 59.6 & 84 & 71.2 & 203 & 83.2 & $<0.001$ \\
\hline Years living in the house (mean \pm SD) & \multicolumn{2}{|c|}{$26.5 \pm 16.2$} & \multicolumn{2}{|c|}{$23.8 \pm 15.3$} & \multicolumn{2}{|c|}{$17.4 \pm 12.8$} & \multicolumn{2}{|c|}{$35.3 \pm 15.5$} & $<0.001$ \\
\hline \multicolumn{10}{|l|}{ Health-related variables } \\
\hline Chronic conditions* (\% yes) & 510 & 69.4 & 261 & 69.6 & 84 & 71.8 & 165 & 67.9 & 0.748 \\
\hline Disability (\% yes) & 237 & 32.2 & 79 & 21.1 & 27 & 23.1 & 131 & 53.5 & $<0.001$ \\
\hline Smoking cigarettes or narghile (\% yes) & 214 & 28.9 & 98 & 26.1 & 26 & 22.0 & 90 & 36.6 & 0.004 \\
\hline
\end{tabular}

*Chronic conditions include one or more of the following medical conditions: hypertension, diabetes, cardiovascular and cerebrovascular diseases, arteriosclerosis problems, renal problems, and cancer. 
TABLE 2 Comparison of social capital and economic security indicators across Nabaa, Hey El-Sellom, and Burj El-Barajneh camp, Urban Health Study, Beirut, 2003.

\begin{tabular}{|c|c|c|c|c|}
\hline Concept and indicator & $\begin{array}{c}\text { Total } \\
(\%)\end{array}$ & $\begin{array}{c}\text { Nabaa } \\
(\%)\end{array}$ & $\begin{array}{c}\text { Hey El- } \\
\text { Sellom (\%) }\end{array}$ & $\begin{array}{c}\text { Burj El- } \\
\text { Bararajneh } \\
(\%)\end{array}$ \\
\hline \multicolumn{5}{|l|}{ Social Capital } \\
\hline \multicolumn{5}{|l|}{ Locational capital } \\
\hline Happy living in neighborhood/ neighborhood satisfaction (yes) & 74.7 & 84.8 & 77.1 & $58.1^{* *}$ \\
\hline Perception of services in the area-good local schools (yes) & 64.2 & 77.9 & $58.5^{* *}$ & $45.9^{* *}$ \\
\hline Perception of services in the area-good local infrastructure (yes) & 49.7 & 62.8 & $39.8^{* *}$ & $34.6^{* *}$ \\
\hline Perception of services in the area-good waste management (yes) & 70.3 & 72.3 & $48.3^{* *}$ & 77.6 \\
\hline \multicolumn{5}{|l|}{ Social anchorage } \\
\hline Feeling like you belong here (yes) & 66.9 & 51.9 & $74.6^{* *}$ & $86.2^{* *}$ \\
\hline Knowing people in neighborhood (yes) & 52.8 & 60.6 & $18.6^{* *}$ & 57.3 \\
\hline Feeling safe walking alone at night (yes) & 85.3 & 88.5 & $78.8^{* *}$ & 83.3 \\
\hline No exposure to physical assaults/ verbal harassment (yes) & 84.2 & 79.8 & 83.1 & $91.5^{* *}$ \\
\hline \multicolumn{5}{|l|}{ Social participation } \\
\hline Belong to social/community group/neighborhood union (yes) & 11.8 & 16.5 & $2.5^{* *}$ & $8.9^{* *}$ \\
\hline Attendance of weekly religious activities (yes) & 32.6 & 33.7 & 28.2 & 33.1 \\
\hline \multicolumn{5}{|l|}{ Civic trust } \\
\hline Trusting people in area (yes) & 21.0 & 21.0 & $7.6^{* *}$ & 27.2 \\
\hline Trusting merchants (yes) & 56.8 & 49.7 & 56.4 & $67.9^{* *}$ \\
\hline $\begin{array}{l}\text { One need not be vigilant in dealing with others in community } \\
\text { (yes) }\end{array}$ & 21.0 & 31.4 & $11.9^{* *}$ & $9.4^{* *}$ \\
\hline \multicolumn{5}{|l|}{ Reciprocity } \\
\hline People in this community help each other (yes) & 34.5 & 46.8 & $17.1^{* *}$ & $23.9^{* *}$ \\
\hline Any exchange of non-financial favors last month (yes) & 31.3 & 41.4 & $18.8^{* *}$ & $21.6^{* *}$ \\
\hline \multicolumn{5}{|l|}{ Hypothetical social support } \\
\hline Can turn to someone in case of illness (yes) & 94.2 & 97.6 & $82.2^{* *}$ & 94.7 \\
\hline Can turn to someone in case of financial hardship (yes) & 71.4 & 79.0 & $61.9^{* *}$ & $64.2^{* *}$ \\
\hline Can turn to someone for help with personal hardships (yes) & 76.0 & 83.2 & $62.7^{* *}$ & $71.1^{* *}$ \\
\hline Can turn to someone if feels like going out (yes) & 75.5 & 85.4 & $53.4^{* *}$ & $71.0^{* *}$ \\
\hline \multicolumn{5}{|l|}{ Social networks } \\
\hline Good relation with children (yes) & 92.3 & 91.7 & 95.7 & 91.4 \\
\hline Good relation with relatives/friends/neighbors (yes) & 91.6 & 95.7 & $88.9^{* *}$ & $86.5^{* *}$ \\
\hline Social capital composite score $(m e a n \pm S D)^{\dagger}$ & $12.6 \pm 3.0$ & $13.5 \pm 3.0$ & $10.6^{* *} \pm 2.7$ & $12.1^{* *} \pm 2.6$ \\
\hline \multicolumn{5}{|l|}{ Economic security } \\
\hline Current employment (yes) & 17.0 & 16.2 & 13.6 & 19.9 \\
\hline Monthly income exceeding 450,000 Lebanese pounds (yes) & 71.2 & 84.6 & 79.7 & $46.8^{* *}$ \\
\hline Income from self/spouse (yes) & 24.9 & 24.5 & 25.4 & 25.2 \\
\hline Income assistance from children (yes) & 68.5 & 68.6 & 61.5 & 71.5 \\
\hline Income assistance from charity (yes) & 20.0 & 4.8 & 1.7 & $52.0^{* *}$ \\
\hline Income assistance from relatives or friends (yes) & 11.4 & 11.4 & $4.3^{*}$ & 14.6 \\
\hline Income dependents (yes) & 50.9 & 42.5 & 41.5 & $68.3^{* *}$ \\
\hline Economic security composite score $(\text { mean } \pm S D)^{+}$ & $3.6 \pm 1.4$ & $4.0 \pm 1.1$ & $4.1 \pm 1.1$ & $2.9 \pm 1.5^{* *}$ \\
\hline
\end{tabular}

\footnotetext{
${ }^{*} \mathrm{p}$-value $<0.05$ (bivariate analyses using Nabaa as a reference category).

${ }^{* *}$ p-value $<0.01$ (bivariate analyses using Nabaa as a reference category).
} 
${ }^{\dagger}$ Composite scores for the social capital and the economic security constructs were generated by summing up indicators describing each of these constructs. Favorable outcomes for each indicator were coded ' 1 ' while negative outcomes were coded ' 0 '. It bears notice that for certain indicators, the favorable outcome might not have been necessarily used to describe that indicator in the table. 
TABLE 3 Ordinal logistic regression analyses for poorer self-rated health, Urban Health Study, Beirut, 2003.

\begin{tabular}{|c|c|c|c|c|c|c|c|c|}
\hline \multirow{2}{*}{$\begin{array}{c}\text { Variables (reference } \\
\text { category) }\end{array}$} & \multicolumn{2}{|c|}{ Model 1} & \multicolumn{2}{|c|}{ Model 2} & \multicolumn{2}{|c|}{ Model 3} & \multicolumn{2}{|c|}{ Model 4} \\
\hline & $O R$ & $95 \% \mathrm{Cl}$ & $O R$ & $95 \% \mathrm{Cl}$ & $O R$ & $95 \% \mathrm{Cl}$ & $O R$ & $95 \% \mathrm{Cl}$ \\
\hline \multicolumn{9}{|l|}{ Community (Nabaa) } \\
\hline Hey El-Sellom & 2.07 & $1.36-3.16$ & 2.12 & $1.39-3.24$ & 1.46 & $0.94-2.23$ & 1.49 & $0.96-2.32$ \\
\hline Burj El-Barajneh & 1.72 & $1.20-2.49$ & 1.42 & $0.96-2.08$ & 1.45 & $1.00-2.12$ & 1.18 & $0.80-1.76$ \\
\hline \multicolumn{9}{|l|}{ Age (60-64) } \\
\hline $65-69$ & 1.46 & $1.02-2.09$ & 1.34 & $0.93-1.92$ & 1.39 & $0.97-2.00$ & 1.27 & $0.88-1.84$ \\
\hline $70+$ & 1.27 & $0.90-1.80$ & 1.12 & $0.78-1.60$ & 1.26 & $0.88-1.79$ & 1.10 & $0.77-1.59$ \\
\hline \multicolumn{9}{|l|}{ Sex (female) } \\
\hline Male & 0.70 & $0.50-0.97$ & 0.72 & $0.51-1.00$ & 0.80 & $0.57-1.12$ & 0.81 & $0.58-1.14$ \\
\hline \multicolumn{9}{|l|}{$\begin{array}{l}\text { Education (formal } \\
\text { schooling) }\end{array}$} \\
\hline No & 1.19 & $0.86-1.66$ & 1.15 & $0.83-1.61$ & 1.18 & $0.85-1.66$ & 1.14 & $0.81-1.60$ \\
\hline \multicolumn{9}{|l|}{$\begin{array}{l}\text { History of displacement } \\
\text { (none) }\end{array}$} \\
\hline Yes & 1.18 & $0.86-1.61$ & 1.18 & $0.86-1.61$ & 1.24 & $0.90-1.69$ & 1.22 & $0.89-1.68$ \\
\hline Years living in house & 1.00 & $0.99-1.01$ & 1.00 & $0.99-1.01$ & 1.01 & $1.00-1.02$ & 1.01 & $1.00-1.02$ \\
\hline \multicolumn{9}{|l|}{ Smoking (no) } \\
\hline Yes & 1.25 & $0.89-1.75$ & 1.25 & $0.88-1.75$ & 1.16 & $0.82-1.63$ & 1.16 & $0.82-1.64$ \\
\hline Chronic conditions & 1.42 & $1.29-1.57$ & 1.41 & $1.28-1.56$ & 1.43 & $1.29-1.59$ & 1.42 & $1.28-1.57$ \\
\hline \multicolumn{9}{|l|}{ Disability (no) } \\
\hline Yes & 2.60 & $1.85-3.65$ & 2.47 & $1.76-3.48$ & 2.59 & $1.84-3.65$ & 2.46 & $1.74-3.47$ \\
\hline Economic security score & & & 0.81 & $0.72-0.92$ & & & 0.81 & $0.72-0.92$ \\
\hline Social capital score & & & & & 0.87 & $0.82-0.91$ & 0.86 & $0.82-0.91$ \\
\hline
\end{tabular}

Model 1: Association between community and poorer SRH adjusting for age, gender, education, history of displacement, years living in house, smoking, chronic conditions, and disability.

Model 2: Role of economic security in explaining the association between community and poorer SRH after adjusting for confounders (age, gender, education, history of displacement, years living in house, smoking, chronic conditions, and disability).

Model 3: Role of social capital in explaining the association between community and poorer SRH after adjusting for confounders (age, gender, education, history of displacement, years living in house, smoking, chronic conditions, and disability).

Model 4: Relative contribution of economic security and social capital to the association between community and poorer SRH after adjusting for confounders (age, gender, education, history of displacement, years living in house, smoking, chronic conditions, and disability). 


\section{Supplementary Online Material}

Self-rated health disparities among disadvantaged older adults in ethnicallydiverse urban neighborhoods in a Middle Eastern country 
TABLE S1 Cross-community comparisons for the social capital and economic security indicators and their summative scores using respectively, Nabaa and Burj El-Barajneh camp as the reference community, Urban Health Study, Beirut, 2003.

\begin{tabular}{|c|c|c|c|c|}
\hline \multirow{2}{*}{ Reference community } & \multicolumn{2}{|c|}{ Nabaa (reference) } & \multicolumn{2}{|c|}{ Burj El-Barajneh (reference) } \\
\hline & Hey El-Sellom & Burj El-Barajneh & Nabaa & Hey El-Sellom \\
\hline Concept and indicator & OR $(95 \% \mathrm{CI})$ & OR $(95 \% \mathrm{CI})$ & OR $(95 \% \mathrm{CI})$ & OR $(95 \% \mathrm{CI})$ \\
\hline \multicolumn{5}{|l|}{ Social Capital } \\
\hline \multicolumn{5}{|l|}{ Locational capital } \\
\hline Happy living in neighborhood/ neighborhood satisfaction & $0.60(0.36-1.00)$ & $0.25(0.17-0.36)^{* *}$ & $4.03(2.76-5.89)^{* *}$ & $2.43(1.47-4.00)^{* *}$ \\
\hline Perception of services in the area- good local schools & $0.40(0.26-0.62)^{* *}$ & $0.24(0.17-0.34)^{* *}$ & $4.15(2.93-5.89)^{* *}$ & $1.66(1.06-2.58)^{*}$ \\
\hline Perception of services in the area- good local infrastructure & $0.39(0.26-0.60)^{* *}$ & $0.31(0.22-0.44)^{* *}$ & $3.19(2.28-4.47)^{* *}$ & $1.25(0.80-1.97)$ \\
\hline Perception of services in the area- good waste management & $0.36(0.23-0.55)^{* *}$ & $1.32(0.91-1.93)$ & $0.75(0.52-1.10)$ & $0.27(0.17-0.43)^{* * *}$ \\
\hline \multicolumn{5}{|l|}{ Social anchorage } \\
\hline Feeling like you belong here & $2.72(1.72-4.32)^{* *}$ & $5.79(3.82-8.76)^{* *}$ & $0.17(0.11-0.26)^{* *}$ & $0.47(0.27-0.82)^{* * *}$ \\
\hline Knowing people in neighborhood & $0.15(0.09-0.25)^{* *}$ & $0.87(0.63-1.21)$ & $1.15(0.83-1.59)$ & $0.17(0.10-0.29)^{* *}$ \\
\hline Feeling safe walking alone at night & $0.48(0.28-0.83)^{* *}$ & $0.65(0.41-1.03)$ & $1.54(0.97-2.45)$ & $0.74(0.43-1.29)$ \\
\hline No exposure to physical assaults/ verbal harassment & $1.24(0.72-2.14)$ & $2.71(1.62-4.53)^{* *}$ & $0.37(0.22-0.61)^{* * *}$ & $0.46(0.24-0.88)^{*}$ \\
\hline \multicolumn{5}{|l|}{ Social participation } \\
\hline Belong to social/community group/neighborhood union & $0.13(0.04-0.43)^{* *}$ & $0.50(0.30-0.83)^{* *}$ & $2.01(1.20-3.37)^{* *}$ & $0.27(0.08-0.91)^{*}$ \\
\hline Attendance of weekly religious activities & $0.77(0.49-1.22)$ & $0.97(0.69-1.37)$ & $1.03(0.73-1.45)$ & $0.80(0.49-1.29)$ \\
\hline \multicolumn{5}{|l|}{ Civic trust } \\
\hline Trusting people in area & $0.31(0.15-0.64)^{* *}$ & $1.41(0.97-2.05)$ & $0.71(0.49-1.03)$ & $0.22(0.11-0.46)^{* *}$ \\
\hline Trusting merchants & $1.31(0.86-1.99)$ & $2.14(1.53-2.99)^{* *}$ & $0.47(0.33-0.65)^{* * *}$ & $0.61(0.39-0.96)^{*}$ \\
\hline One need not be vigilant in dealing with others in community & $0.29(0.16-0.54)^{* *}$ & $0.23(0.14-0.36)^{* *}$ & $4.43(2.74-7.17)^{* *}$ & $1.30(0.65-2.64)$ \\
\hline \multicolumn{5}{|l|}{ Reciprocity } \\
\hline People in this community help each other & $0.23(0.14-0.39)^{* *}$ & $0.36(0.25-0.51)^{* *}$ & $2.79(1.95-3.98)^{* * *}$ & $0.65(0.37-1.15)$ \\
\hline Any exchange of non-financial favors last month & $0.33(0.20-0.54)^{* *}$ & $0.39(0.27-0.56)^{* *}$ & $2.56(1.78-3.70)^{* *}$ & $0.84(0.48-1.46)$ \\
\hline \multicolumn{5}{|l|}{ Hypothetical social support } \\
\hline Can turn to someone in case of illness & $0.11(0.05-0.25)^{* *}$ & $0.44(0.18-1.04)$ & $2.27(0.96-5.41)$ & $0.26(0.12-0.53)^{* * *}$ \\
\hline Can turn to someone in case of financial hardship & $0.43(0.28-0.67)^{* *}$ & $0.48(0.33-0.68)^{* *}$ & $2.09(1.46-3.00)^{* * *}$ & $0.90(0.57-1.42)$ \\
\hline Can turn to someone for help with personal hardships & $0.34(0.21-0.54)^{* *}$ & $0.50(0.34-0.73)^{* *}$ & $2.02(1.37-2.97)^{* *}$ & $0.68(0.43-1.08)$ \\
\hline Can turn to someone if feels like going out & $0.20(0.12-0.31)^{* *}$ & $0.42(0.28-0.62)^{* *}$ & $2.38(1.60-3.54)^{* *}$ & $0.47(0.30-0.74)^{* * *}$ \\
\hline \multicolumn{5}{|l|}{ Social networks } \\
\hline Good relation with children & $2.02(0.77-5.33)$ & $0.96(0.54-1.72)$ & $1.04(0.58-1.85)$ & $2.10(0.77-5.72)$ \\
\hline Good relation with relatives/friends/neighbors & $0.36(0.17-0.77)^{* *}$ & $0.29(0.15-0.53)^{* * *}$ & $3.48(1.87-6.48)^{* *}$ & $1.24(0.63-2.47)$ \\
\hline Social capital composite score expressed as $\beta$ ( $95 \% \mathrm{CI})$ & $-2.90(-3.48 ;-2.31)^{* *}$ & $-1.45(-1.90 ;-0.98)^{* *}$ & $1.44(0.99 ; 1.90)^{* *}$ & $-1.45(-2.07 ;-0.82)^{* *}$ \\
\hline \multicolumn{5}{|l|}{ Economic security } \\
\hline Current employment & $0.81(0.45-1.47)$ & $1.28(0.85-1.95)$ & $0.78(0.51-1.18)$ & $0.63(0.34-1.16)$ \\
\hline
\end{tabular}


Monthly income exceeding 450,000 Lebanese pounds Income from self/spouse

Income assistance from children

Income assistance from charity

Income assistance from relatives or friends

Income dependents

Economic security composite score expressed as $\beta(95 \% \mathrm{CI})$

*p-value $<0.05$

$0.71(0.42-1.21)$

$1.05(0.65-1.69)$

$0.73(0.47-1.13)$

$0.35(0.08-1.51)$

$0.35(0.13-0.89)$

$0.96(0.63-1.46)$

$0.12(-0.14 ; 0.38)$

$$
\begin{gathered}
0.16(0.11-0.23)^{* *} \\
1.04(0.72-1.51) \\
1.15(0.81-1.64) \\
21.57(12.63-36.85)^{* *} \\
1.33(0.83-2.13)
\end{gathered}
$$

$2.91(2.07-4.07)^{* *}$

$-1.12(-1.33 ;-0.92)^{* *}$
$6.25(4.29-9.09)^{* *}$

$0.96(0.66-1.39)$

$0.87(0.61-1.24)$

$0.05(0.03-0.08)^{* *}$

$0.75(0.47-1.21)$

$0.34(0.24-0.48)^{*}$

$1.12(0.92 ; 1.33)^{*}$
$4.46(2.67-7.46)^{* *}$

$1.01(0.61-1.68)$

$0.64(0.40-1.01)$

$0.02(0.004-0.07)^{* *}$

$0.26(0.10-0.68)^{\text {*** }}$

$0.33(0.21-0.52)^{* *}$

$1.25(0.97 ; 1.53)^{* *}$

** p-value $<0.01$ 
TABLE S2 Supplemental multivariate ordinal logistic regression analyses for poorer selfrated health using Burj El-Barajneh camp as the reference community, Urban Health Study, Beirut, 2003.

\begin{tabular}{|c|c|c|c|c|c|c|c|c|}
\hline \multirow{2}{*}{$\begin{array}{l}\text { Variables (reference } \\
\text { category) }\end{array}$} & \multicolumn{2}{|c|}{ Model 1} & \multicolumn{2}{|c|}{ Model 2} & \multicolumn{2}{|c|}{ Model 3} & \multicolumn{2}{|c|}{ Model 4} \\
\hline & $O R$ & $95 \% C I$ & $O R$ & $95 \% C I$ & $O R$ & $95 \% C I$ & $O R$ & $95 \% C I$ \\
\hline \multicolumn{9}{|c|}{ Community (Burj El-Barajneh) } \\
\hline Nabaa & 0.58 & $0.40-0.84$ & 0.71 & $0.48-1.04$ & 0.68 & $0.47-1.00$ & 0.84 & $0.56-1.25$ \\
\hline Hey El-Sellom & 1.20 & $0.73-1.96$ & 1.50 & $0.90-2.50$ & 1.00 & $0.61-1.65$ & 1.25 & $0.75-2.10$ \\
\hline \multicolumn{9}{|l|}{ Age (60-64) } \\
\hline $65-69$ & 1.46 & $1.02-2.09$ & 1.34 & $0.93-1.92$ & 1.39 & $0.97-2.00$ & 1.27 & $0.88-1.84$ \\
\hline $70+$ & 1.27 & $0.90-1.80$ & 1.12 & $0.78-1.60$ & 1.26 & $0.88-1.79$ & 1.10 & $0.77-1.59$ \\
\hline \multicolumn{9}{|l|}{ Sex (female) } \\
\hline Male & 0.70 & $0.50-0.97$ & 0.72 & $0.51-1.00$ & 0.80 & $0.57-1.12$ & 0.81 & $0.58-1.14$ \\
\hline \multicolumn{9}{|c|}{ Education (formal schooling) } \\
\hline No & 1.19 & $0.86-1.66$ & 1.15 & $0.83-1.61$ & 1.18 & $0.85-1.66$ & 1.14 & $0.81-1.60$ \\
\hline \multicolumn{9}{|c|}{ History of displacement (none) } \\
\hline Yes & 1.18 & $0.86-1.61$ & 1.18 & $0.86-1.61$ & 1.24 & $0.90-1.69$ & 1.22 & $0.89-1.68$ \\
\hline Years living in house & 1.00 & $0.99-1.01$ & 1.00 & $0.99-1.01$ & 1.01 & $1.00-1.02$ & 1.01 & $1.00-1.02$ \\
\hline \multicolumn{9}{|l|}{ Smoking (no) } \\
\hline Yes & 1.25 & $0.89-1.75$ & 1.25 & $0.88-1.75$ & 1.16 & $0.82-1.63$ & 1.16 & $0.82-1.64$ \\
\hline Chronic conditions & 1.42 & $1.29-1.57$ & 1.41 & $1.28-1.56$ & 1.43 & $1.29-1.59$ & 1.42 & $1.28-1.57$ \\
\hline \multicolumn{9}{|l|}{ Disability (no) } \\
\hline Yes & 2.60 & $1.85-3.65$ & 2.47 & $1.76-3.48$ & 2.59 & $1.84-3.65$ & 2.46 & $1.74-3.47$ \\
\hline Economic security score & & & 0.81 & $0.72-0.92$ & & & 0.81 & $0.72-0.92$ \\
\hline Social capital score & & & & & 0.87 & $0.82-0.91$ & 0.86 & $0.82-0.91$ \\
\hline
\end{tabular}

Model 1: Association between community and poorer SRH adjusting for age, gender, education, history of displacement, years living in house, smoking, chronic conditions, and disability.

Model 2: Role of economic security in explaining the association between community and poorer SRH after adjusting for confounders (age, gender, education, history of displacement, years living in house, smoking, chronic conditions, and disability).

Model 3: Role of social capital in explaining the association between community and poorer SRH after adjusting for confounders (age, gender, education, history of displacement, years living in house, smoking, chronic conditions, and disability).

Model 4: Relative contribution of economic security and social capital to the association between community and poorer SRH after adjusting for confounders (age, gender, education, history of displacement, years living in house, smoking, chronic conditions, and disability). 
TABLE S3 Sensitivity analysis assessing the robustness of our multivariate regression analyses to the use of the 3-points ordinal self-rated health measure as opposed to the original 5-point likert scale measure.

\begin{tabular}{|c|c|c|c|c|}
\hline \multirow[t]{2}{*}{ Variables (reference category) } & \multicolumn{2}{|c|}{$\begin{array}{l}\text { Model using a 3- } \\
\text { point Likert scale } \\
\text { for SRH }\end{array}$} & \multicolumn{2}{|c|}{$\begin{array}{l}\text { Model using a 5- } \\
\text { point Likert scale } \\
\text { for SRH }\end{array}$} \\
\hline & $O R$ & $95 \% C I$ & $O R$ & $95 \% C I$ \\
\hline \multicolumn{5}{|l|}{ Community (Nabaa) } \\
\hline Hey El-Sellom & 1.49 & $0.96-2.32$ & 1.42 & $0.93-2.17$ \\
\hline Burj El-Barajneh & 1.18 & $0.80-1.76$ & 1.08 & $0.74-1.59$ \\
\hline \multicolumn{5}{|l|}{ Age (60-64) } \\
\hline $65-69$ & 1.27 & $0.88-1.84$ & 1.22 & $0.86-1.73$ \\
\hline $70+$ & 1.10 & $0.77-1.59$ & 1.10 & $0.78-1.56$ \\
\hline \multicolumn{5}{|l|}{ Sex (female) } \\
\hline Male & 0.81 & $0.58-1.14$ & 0.84 & $0.61-1.16$ \\
\hline \multicolumn{5}{|l|}{ Education (formal schooling) } \\
\hline No & 1.14 & $0.81-1.60$ & 1.13 & $0.82-1.56$ \\
\hline \multicolumn{5}{|l|}{ History of displacement (none) } \\
\hline Yes & 1.22 & $0.89-1.68$ & 1.18 & $0.87-1.59$ \\
\hline Years living in house & 1.01 & $1.00-1.02$ & 1.01 & $1.00-1.02$ \\
\hline \multicolumn{5}{|l|}{ Smoking (no) } \\
\hline Yes & 1.16 & $0.82-1.64$ & 1.14 & $0.82-1.59$ \\
\hline Chronic conditions & 1.42 & $1.28-1.57$ & 1.38 & $1.26-1.52$ \\
\hline \multicolumn{5}{|l|}{ Disability (no) } \\
\hline Yes & 2.46 & $1.74-3.47$ & 2.60 & $1.86-3.63$ \\
\hline Social capital score & 0.86 & $0.82-0.91$ & 0.86 & $0.82-0.91$ \\
\hline Economic security score & 0.81 & $0.72-0.92$ & 0.82 & $0.73-0.92$ \\
\hline Number of observations & 729 & & 729 & \\
\hline $\mathrm{LR} \mathrm{Chi}^{2}(\mathrm{df}=13)$ & 202.62 & & 209.48 & \\
\hline $\mathrm{P}$-value & 0.000 & & 0.000 & \\
\hline Pseudo $\mathrm{R}^{2}$ & $12.66 \%$ & & $10.43 \%$ & \\
\hline
\end{tabular}


TABLE S4 Comparison of community-level and individual-level social capital indicators and economic security indicators across Nabaa, Hey El-Sellom, and Burj El-Barajneh camp, Urban Health Study, Beirut, 2003.

\begin{tabular}{|c|c|c|c|c|c|}
\hline Concept and indicator & $\begin{array}{l}\text { Total } \\
(\%)\end{array}$ & $\begin{array}{c}\text { Nabaa } \\
(\%)\end{array}$ & $\begin{array}{l}\text { Hey El- } \\
\text { Sellom } \\
(\%)\end{array}$ & $\begin{array}{c}\text { Burj El- } \\
\text { Bararajneh } \\
(\%)\end{array}$ & p-value \\
\hline \multicolumn{6}{|l|}{ Social Capital } \\
\hline \multicolumn{6}{|l|}{ Community-level indicators } \\
\hline Happy living in neighborhood/ neighborhood satisfaction & 74.7 & 84.8 & 77.1 & 58.1 & $<0.001$ \\
\hline Perception of services in the area- good local schools & 64.2 & 77.9 & 58.5 & 45.9 & $<0.001$ \\
\hline Perception of services in the area- good local infrastructure & 49.7 & 62.8 & 39.8 & 34.6 & $<0.001$ \\
\hline Perception of services in the area- good waste management & 70.3 & 72.3 & 48.3 & 77.6 & $<0.001$ \\
\hline Feeling safe walking alone at night & 85.3 & 88.5 & 78.8 & 83.3 & 0.020 \\
\hline No exposure to physical assaults/ verbal harassment & 84.2 & 79.8 & 83.1 & 91.5 & $<0.001$ \\
\hline One need not be vigilant in dealing with others in community & 21.0 & 31.4 & 11.9 & 9.4 & $<0.001$ \\
\hline People in this community help each other & 34.5 & 46.8 & 17.1 & 23.9 & $<0.001$ \\
\hline Community-level social capital composite score (mean \pm SD) & $4.8 \pm 1.6$ & $5.4 \pm 1.5$ & $4.1 \pm 1.7$ & $4.2 \pm 1.4$ & $<0.000$ \\
\hline \multicolumn{6}{|l|}{ Individual-level indicators } \\
\hline Feeling like you belong here & 66.9 & 51.9 & 74.6 & 86.2 & $<0.001$ \\
\hline Knowing people in neighborhood & 52.8 & 60.6 & 18.6 & 57.3 & $<0.001$ \\
\hline Belong to social/community group/neighborhood union & 11.8 & 16.5 & 2.5 & 8.9 & $<0.001$ \\
\hline Attendance of weekly religious activities & 32.6 & 33.7 & 28.2 & 33.1 & 0.534 \\
\hline Trusting people in area $<0$ & 21.0 & 21.0 & 7.6 & 27.2 & $<0.001$ \\
\hline Trusting merchants & 56.8 & 49.7 & 56.4 & 67.9 & $<0.001$ \\
\hline Any exchange of non-financial favors last month & 31.3 & 41.4 & 18.8 & 21.6 & $<0.001$ \\
\hline Can turn to someone in case of illness & 94.2 & 97.6 & 82.2 & 94.7 & $<0.001$ \\
\hline Can turn to someone in case of financial hardship & 71.4 & 79.0 & 61.9 & 64.2 & $<0.001$ \\
\hline Can turn to someone for help with personal hardships & 76.0 & 83.2 & 62.7 & 71.1 & $<0.001$ \\
\hline Can turn to someone if feels like going out & 75.5 & 85.4 & 53.4 & 71.0 & $<0.001$ \\
\hline Good relation with children & 92.3 & 91.7 & 95.7 & 91.4 & 0.300 \\
\hline Good relation with relatives/friends/neighbors & 91.6 & 95.7 & 88.9 & 86.5 & $<0.001$ \\
\hline Individual-level social capital composite score (mean \pm SD) & $7.7 \pm 2.1$ & $8.1 \pm 2.1$ & $6.5 \pm 1.9$ & $7.8 \pm 1.9$ & $<0.000$ \\
\hline \multicolumn{6}{|l|}{ Economic security } \\
\hline Current employment & 17.0 & 16.2 & 13.6 & 19.9 & 0.268 \\
\hline Monthly income exceeding 450,000 Lebanese pounds & 71.2 & 84.6 & 79.7 & 46.8 & $<0.001$ \\
\hline Income from self/spouse & 24.9 & 24.5 & 25.4 & 25.2 & 0.967 \\
\hline Income assistance from children & 68.5 & 68.6 & 61.5 & 71.5 & 0.158 \\
\hline Income assistance from charity & 20.0 & 4.8 & 1.7 & 52.0 & $<0.001$ \\
\hline Income assistance from relatives or friends & 11.4 & 11.4 & 4.3 & 14.6 & 0.015 \\
\hline Income dependents & 50.9 & 42.5 & 41.5 & 68.3 & $<0.001$ \\
\hline Economic security composite score (mean $\_$SD) & $3.6 \pm 1.4$ & $4.0 \pm 1.1$ & $4.1 \pm 1.1$ & $2.9 \pm 1.5$ & $<0.001$ \\
\hline
\end{tabular}


TABLE S5 Sensitivity analyses examining the relative contribution of social capital community-level and individual-level constructs on the association between community and poorer self-rated health SRH, Urban Health Study, Beirut, 2003.

\begin{tabular}{|c|c|c|c|c|c|c|c|c|c|c|}
\hline \multirow{2}{*}{$\begin{array}{l}\text { Variables (reference } \\
\text { category) }\end{array}$} & \multicolumn{2}{|c|}{ Model 1} & \multicolumn{2}{|c|}{ Model 2} & \multicolumn{2}{|c|}{ Model 3} & \multicolumn{2}{|c|}{ Model 4} & \multicolumn{2}{|c|}{ Model 5} \\
\hline & OR & $95 \% C I$ & $O R$ & $95 \% C I$ & $O R$ & $95 \% C I$ & $O R$ & $95 \% C I$ & $O R$ & $95 \% C I$ \\
\hline \multicolumn{11}{|l|}{ Community (Nabaa) } \\
\hline Hey El-Sellom & 2.07 & $1.36-3.16$ & 2.12 & $1.39-3.24$ & 1.59 & $0.94-2.23$ & 1.71 & $1.11-2.64$ & 1.48 & $0.96-2.32$ \\
\hline Burj El-Barajneh & 1.72 & $1.20-2.49$ & 1.42 & $0.96-2.08$ & 1.35 & $1.00-2.12$ & 1.70 & $1.18-2.46$ & 1.16 & $0.80-1.76$ \\
\hline \multicolumn{11}{|l|}{ Age (60-64) } \\
\hline $65-69$ & 1.46 & $1.02-2.09$ & 1.34 & $0.93-1.92$ & 1.39 & $0.97-2.00$ & 1.43 & $0.99-2.05$ & 1.27 & $0.88-1.84$ \\
\hline $70+$ & 1.27 & $0.90-1.80$ & 1.12 & $0.78-1.60$ & 1.34 & $0.88-1.79$ & 1.21 & $0.85-1.72$ & 1.12 & $0.77-1.59$ \\
\hline \multicolumn{11}{|l|}{ Sex (female) } \\
\hline Male & 0.70 & $0.50-0.97$ & 0.72 & $0.51-1.00$ & 0.67 & $0.48-0.93$ & 0.84 & $0.60-1.18$ & 0.79 & $0.58-1.14$ \\
\hline \multicolumn{11}{|l|}{$\begin{array}{l}\text { Education (formal } \\
\text { schooling) }\end{array}$} \\
\hline No & 1.19 & $0.86-1.66$ & 1.15 & $0.83-1.61$ & 1.22 & $0.87-1.70$ & 1.16 & $0.84-1.63$ & 1.15 & $0.81-1.60$ \\
\hline \multicolumn{11}{|l|}{$\begin{array}{l}\text { History of displacement } \\
\text { (none) }\end{array}$} \\
\hline Yes & 1.18 & $0.86-1.61$ & 1.18 & $0.86-1.61$ & 1.26 & $0.91-1.72$ & 1.18 & $0.86-1.61$ & 1.23 & $0.89-1.68$ \\
\hline Years living in house & 1.00 & $0.99-1.01$ & 1.00 & $0.99-1.01$ & 1.00 & $0.99-1.01$ & 1.01 & $0.99-1.02$ & 1.01 & $1.00-1.02$ \\
\hline \multicolumn{11}{|l|}{ Smoking (no) } \\
\hline Yes & 1.25 & $0.89-1.75$ & 1.25 & $0.88-1.75$ & 1.22 & $0.87-1.72$ & 1.16 & $0.83-1.64$ & 1.17 & $0.82-1.64$ \\
\hline Chronic conditions & 1.42 & $1.29-1.57$ & 1.41 & $1.28-1.56$ & 1.44 & $1.30-1.59$ & 1.42 & $1.29-1.57$ & 1.42 & $1.28-1.57$ \\
\hline \multicolumn{11}{|l|}{ Disability (no) } \\
\hline Yes & 2.60 & $1.85-3.65$ & 2.47 & $1.76-3.48$ & 2.66 & $1.88-3.74$ & 2.55 & $1.81-3.60$ & 2.47 & $1.74-3.47$ \\
\hline Economic security score & & & 0.81 & $0.72-0.92$ & & & & & 0.81 & $0.72-0.92$ \\
\hline $\begin{array}{l}\text { Community-level social } \\
\text { capital score }\end{array}$ & & & & & 0.80 & $0.73-0.88$ & & & 0.84 & $0.76-0.93$ \\
\hline $\begin{array}{l}\text { Individual-level social } \\
\text { capital score }\end{array}$ & & & & & & & 0.86 & $0.79-0.92$ & 0.88 & $0.82-0.95$ \\
\hline
\end{tabular}

Model 1: Association between community and poorer SRH adjusting for age, gender, education, history of displacement, years living in house, smoking, chronic conditions, and disability. 
Model 2: Role of economic security in explaining the association between community and poorer SRH after adjusting for confounders (age, gender, education, history of displacement, years living in house, smoking, chronic conditions, and disability).

Model 3: Role of social capital community-level construct in explaining the association between community and poorer SRH after adjusting for confounders (age, gender, education, history of displacement, years living in house, smoking, chronic conditions, and disability).

Model 4: Role of social capital individual-level construct in explaining the association between community and poorer SRH after adjusting for confounders (age, gender, education, history of displacement, years living in house, smoking, chronic conditions, and disability).

Model 4: Relative contribution of economic security and social capital constructs to the association between community and poorer SRH after adjusting for confounders (age, gender, education, history of displacement, years living in house, smoking, chronic conditions, and disability). 